\title{
A PERCEPÇÃO DOS ALUNOS SOBRE O USO DE WEBQUEST NO DESENVOLVIMENTO DA LEITURA HIPERTEXTUAL
}

\author{
José de Ribamar Carvalho Júnior? \\ Silvana Neumann Martins²
}

\section{RESUMO}

A leitura com hipertextos digitais na internet requer habilidade e muito foco. Para alguns leitores, a diversidade de informações disponibilizadas na rede podem promover situações prejudiciais à leitura como a dispersão. Assim, é importante usar ferramentas que possam combater este problema. Neste artigo, a investigação objetivou averiguar as percepções de alunos do Ensino Médio sobre a utilização da ferramenta metodológica Webquest no desenvolvimento da leitura de hipertextos digitais. A abordagem teórica contou com os pressupostos de ciberespaço (LÉVY, 1998); gênero digital e hipertexto (MARCUSCHI, 1999 e 2010; KENSKI, 2008); estratégias de leitura (SOLÉ, 1998); e Webquest (DODGE, 1999 e 2002; BOTTENTUIT JR, 2008 e 2010). Esta é uma pesquisa de natureza quali-quantitativa, com caráter exploratório, sendo caracterizada como estudo de caso. Os sujeitos foram 26 alunos do curso Técnico em Alimentos do IFMA - Campus Zé Doca. Para coletar os dados foram utilizados dois questionários e a observação sistemática. A atividade consistiu na execução de uma Webquest pelos alunos. Durante o processo, observaram-se os procedimentos adotados no desenvolvimento da leitura de hipertextos na internet e, ao término, aplicou-se o questionário. Os resultados obtidos demostraram que a metodologia Webquest é relevante e viável como ferramenta de ensino para desenvolvimento da leitura de hipertexto, pois agrega em sua estrutura uma dinâmica com práticas que fomentam a motivação e despertam o interesse em abrir os hiperlinks, acessar outros textos e aprofundar a leitura, colaborando para que o leitor não se disperse e abandone o texto.

Palavras-chave: Leitura. Hipertexto digital. Webquest.

\section{STUDENTS' PERCEPTION OF WEBQUEST'S USE IN THE DEVELOPMENT OF HYPERTEXTUAL READING}

\begin{abstract}
Reading with digital hypertext on the internet requires skill and a lot of focusing. For some readers, the diversity of information available on the network can promote reading-damaging situations such as distraction. Thus, it is important to use tools that

\footnotetext{
1 Mestrando do Programa de Pós-Graduação em Ensino da Universidade do Vale do Taquari - UNIVATES. E-mail: carvalho.junnior@gmail.com

2 Doutorado em Educação na Pontifícia Universidade Católica do Rio Grande do Sul - PUCRS. Professora dos Programas de Pós-Graduação em Ensino e Ensino de Ciências Exatas da UNIVATES. E-mail: smartins@univates.com
} 
can solve this problem. In this article, the research aimed at investigating the perceptions of high school students about the use of the Webquest methodological tool in the development of digital hypertext reading. The theoretical approach relied on the assumptions of cyberspace (LÉVY, 1998); digital gender and hypertext (MARCUSCHI, 1999 and 2010; KENSKI, 2008); reading strategies (SOLÉ, 1998); and Webquest (DODGE, 1999 and 2002, BOTTENTUIT JR, 2008 and 2010). This is a qualitative-quantitative research, with an exploratory character, being characterized as a case study. The subjects were 26 students of the Technical Course in Food of IFMA - The Federal Institute of Maranhão, Campus of Zé Doca. Two questionnaires and systematic observation were used to collect the data. The activity consisted in the execution of a Webquest by the students. During the process, we observed the procedures adopted in the development of hypertext reading on the Internet and, at the end, the questionnaire was applied. The results obtained demonstrated that the Webquest methodology is relevant and viable as a teaching tool for the development of hypertext reading, since it adds in its structure a dynamic with practices that foster motivation and arouse the interest in opening the hyperlinks. It also accesses other texts and deepens reading, collaborating for the reader not to distract and leave the text.

Keywords: Reading; Digital hypertext; Webquest.

\section{LA PERCEPCIÓN DE LOS ALUMNOS SOBRE EL USO DE WEBQUEST EN EL DESARROLLO DE LA LECTURA HIPERTEXTUAL}

\section{RESUMEN}

La lectura con hipertextos digitales en Internet requiere habilidad y mucho foco. Para algunos lectores, la diversidad de informaciones disponibles en la red pueden promover situaciones perjudiciales a la lectura como la dispersión. Así, es importante utilizar herramientas que puedan combatir este problema. En este artículo, la investigación objetivó averiguar las percepciones de alumnos de la Enseñanza Media sobre la utilización de la herramienta metodológica Webquest en el desarrollo de la lectura de hipertextos digitales. El enfoque teórico contó con los presupuestos de ciberespacio (LÉVY, 1998); el género digital e hipertexto (MARCUSCHI, 1999 y 2010; KENSKI, 2008); estrategias de lectura (SOLÉ, 1998); y la Webquest (DODGE, 1999 y 2002, BOTTENTUIT JR, 2008 y 2010). Esta es una investigación de naturaleza cuali-cuantitativa, con carácter exploratorio, siendo caracterizada como estudio de caso. Los sujetos fueron 26 alumnos del curso Técnico en Alimentos del IFMA - Campus Zé Doca. Para recoger los datos se utilizaron dos cuestionarios y la observación sistemática. La actividad consistió en la ejecución de una Webquest por los alumnos. Durante el proceso, se observaron los procedimientos adoptados en el desarrollo de la lectura de hipertextos en internet y, al término, se aplicó el cuestionario. Los resultados obtenidos demostraron que la metodología Webquest es relevante y viable como herramienta de enseñanza para el desarrollo de la lectura de hipertexto, pues agrega en su estructura una dinámica con prácticas que fomentan la motivación y despiertan el interés en abrir los hipervínculos, acceder a otros textos y profundizar la lectura, colaborando para que el lector no se disperse y abandone el texto.

Palabras clave: Lectura; Hipertexto digital; Webquest. 


\section{INTRODUÇÃO}

A vida em sociedade modificou-se bastante ao longo dos anos. $\mathrm{Na}$ educação, destacam-se mudanças na maneira de ensinar, de aprender e principalmente na forma de ler na contemporaneidade.

O texto impresso contribuiu bastante para $\bigcirc$ desenvolvimento cognitivo e cultural das pessoas por muito tempo, mas, na atualidade, a maneira que as pessoas usam para ler também se modificou, seguindo as transformações que ocorreram na sociedade contemporânea em virtude da inserção e do uso de novas tecnologias de comunicação e informação (NTCl) e seus recursos. Kenski (2013) assinala que a evolução tecnológica não se restringe apenas ao uso das máquinas, mas também à modificação do comportamento de uma pessoa ou de todo um grupo social.

Nesse sentido, é importante destacar o aumento do acesso à tecnologia digital por meio de aparelhos eletrônicos como smartphones, tablets e similares. Com isso, o exercício da leitura em suportes diferentes do livro impresso vem ganhando espaço gradativamente no cotidiano das pessoas. Moraes e Arena (2012) falam da aceitação e utilidade da leitura digital, prática que, para eles, permite o acesso rápido a conteúdos de qualquer natureza e em qualquer lugar do planeta. A condição citada pelas autoras, no caso, a possibilidade de acesso rápido à leitura na internet, pode favorecer o contato do leitor com informações que se atualizam quase que instantaneamente.

A tecnologia e seus recursos digitais têm sido inseridos em várias instituições de ensino, no intuito de colaborar com o desenvolvimento dos educandos, à medida que inseri no ambiente da sala de aula outros meios de acessar conteúdos, interagir socialmente com outras pessoas, compartilhar informações sobre um determinado assunto em tempo real. Nesse sentido, essas tecnologias tendem a disputar com os livros impressos a atenção dos alunos para o exercício da leitura.

Porém, interagir com o ambiente virtual e realizar uma leitura crítica por meio do hipertexto digital, por exemplo, aparenta não ser uma tarefa simples de ser executada, pois alguns alunos podem não conseguir 
apropriar-se desses recursos tecnológicos em benefícios próprios. Alguns fatores colaboram para que a leitura não aconteça de maneira adequada, entre os quais se destaca a dispersão, fator que o ambiente virtual e a enorme variedade de informação podem proporcionar.

Dessa maneira, observou-se a necessidade de sugerir mudanças de atitude no contexto pedagógico das turmas, tanto entre alunos, quanto professores e a inserção de procedimentos que visassem melhorias para o desenvolvimento da leitura, a partir destes fatos, surgiu a motivação para realização desta pesquisa. Este estudo consiste em um recorte de uma pesquisa de mestrado acadêmico (CARVALHO Jr, 2018) que se propôs a inserir nas aulas de Língua Portuguesa, com a intenção de fomentar novas práticas para o desenvolvimento da leitura, uma ferramenta metodológica de pesquisa na internet, denominada Webquest (WQ), com hipertextos digitais, sob orientação docente e com foco na aprendizagem por colaboração.

Neste artigo, como objetivo geral, detemo-nos a averiguar as percepções dos alunos sobre o uso da ferramenta metodológica Webquest e a leitura de hipertexto digital. Para tal, foram explorados os seguintes os objetivos específicos: 1) Desenvolver os elementos estruturais de uma Webquest com alunos do Ensino Médio; 2) Averiguar os impactos da utilização da ferramenta metodológica Webquest na leitura de hipertextos digitais.

Diante dos aspectos destacados anteriormente, este artigo traz em seu bojo para reflexão as percepções dos alunos do curso Técnico em Alimentos do IFMA-Zé Doca, sobre o uso da ferramenta Webquest no desenvolvimento da leitura hipertextual digital. Dessa forma, essa pesquisa foi estruturada da seguinte forma: Primeiramente temos a descrição da metodologia adotada; Em seguida, apresentamos os resultados e a discussão; e por último, a conclusão. 


\section{METODOLOGIA}

Este artigo é fruto de uma pesquisa de cunho exploratória com abordagem qualiquantitativa, que se propôs a realizar uma investigação com um grupo de alunos do Ensino Médio de uma escola da rede pública em uma cidade no interior do Estado do Maranhão.

Quanto aos procedimentos técnicos adotados, esta pesquisa se caracterizou como estudo de caso, em que é necessário estudar um caso específico como um todo. Dessa maneira, Marconi e Lakatos (2016) orientam que este procedimento é útil para esclarecer fenômenos pouco conhecidos.

Para alcançar os objetivos propostos, inicialmente foi aplicado um questionário com 11 perguntas abertas e de múltipla escolha, em que buscou-se saber $o$ que os alunos entendiam por hipertexto e que procedimentos adotavam para ler, seguido da execução de uma Webquest com 26 alunos do curso Técnico em Alimentos no laboratório de informática da escola. A Webquest trabalhada com os alunos foi idealizada e construída pelo professor e teve como tema central: as eleições para o governo do Estado do Maranhão em 2018.

A turma foi uniformemente dividida em dois grupos que tiveram como tarefa, a organização de toda campanha eleitoral de seus respectivos candidatos ao governo. Para tal, foi estabelecido como procedimentos, a realização de pesquisas na internet, em sites pré-selecionados e elencados pelo professor na intenção de obter informações que fomentassem a elaboração de propostas de governo que foram apresentadas e defendidas em um debate em sala de aula. Os conteúdos disponibilizados nesses sites eram referentes a cada área política que os candidatos deveriam propor melhorias, tais como: Educação, Ciência, Saúde, Esporte e Lazer, Infraestrutura, Cultura e Meio ambiente. Os textos acessados a partir dos sites indicados, foram apresentados em formato de Hipertexto digital, contendo links que davam acesso a outros textos, todos disponíveis na internet.

A turma participante foi escolhida por sorteio, critério utilizado para manter a imparcialidade e isenção na escolha dos sujeitos da pesquisa. 
Durante a atividade, para auxiliar o seu andamento, foi utilizado um roteiro de observação para registrar como o hiperleitor procedia para ler com auxílio da ferramenta Webquest. Ao término, foi aplicado o segundo questionário a fim de averiguar os impactos da utilização da ferramenta Webquest na leitura de hipertexto digital.

Para a análise dos dados foi utilizada uma aproximação com a técnica da análise de conteúdo (BARDIN, 2011), a qual colabora para visualizar e entender melhor os dados coletados. Para a autora: "[...] desde que se começou a lidar com comunicações, que se pretende compreender para além dos seus significados imediatos, parecendo útil o recurso à análise de conteúdo" (BARDIN, 2011, p. 34). Além disso, valeu-se da estatística descritiva (GUEDES, et al., 2005) para analisar os gráficos.

Dessa forma, foi possível selecionar o material que seria analisado em conformidade com os objetivos e questões que pudessem responder ao problema de pesquisa. Os resultados serão apresentados a seguir.

\section{RESULTADOS E DISCUSSÕES}

Neste artigo, apresentam-se os resultados e a discussões dos dados obtidos na pesquisa em conformidade com os objetivos específicos. Para facilitar a compreensão, disponibiliza-se nesta seção uma breve fundamentação dos argumentos que serão expostos no decorrer da análise. Entende-se que, dessa maneira, a sistematização da análise fica mais organizada e melhora a compreensão.

A análise dos dados coletados com os alunos investigados na pesquisa foi organizada em duas categorias, de acordo com os temas que auxiliam a compreensão dos objetivos propostos neste estudo. Sendo elas:1) Navegando por conexões hipertextuais; 2) A Webquest "Eleições 2018 - Um Maranhão melhor para todos" em foco

A primeira, enfoca as atitudes dos alunos investigados ao encontrar um hiperlink durante a leitura do hipertexto digital. A segunda analisa o uso da Webquest como ferramenta metodológica para auxiliar o desenvolvimento da leitura hipertextual digital. Dessa maneira, antes de prosseguir, optou-se 
por definir a concepção de leitura adotada neste estudo. Para tal, indagouse:

Mas afinal, o que é leitura?

Ao tratar sobre o tema, alguns autores apresentam dificuldades em entender e retratar sua mecânica. Quanto a isso, Diesel $(2016$, p.16) orienta que: "aprender a ler não é fácil e dificilmente se dá de forma espontânea". Complementando essa ideia, Lemos (2011, p.26) explica que: "O processo da leitura é cognitivo, acontece dentro da mente humana e, por isso, é um processo interno que dificilmente poderá ser entendido na sua totalidade".

A fim de atingir os propósitos deste estudo, cabe complementar o conceito de leitura, a partir dos estudos de Solé (1998). Com base em tais fundamentações, convém elaborar o conceito de leitura que norteia este trabalho. Assim, é possível esclarecer a linha de pensamento que se evidencia neste estudo ao empregar ferramentas metodológicas para o desenvolvimento da leitura.

Ler, não é somente decifrar códigos linguísticos materializados na palavra. Há outros fatores que, juntos, constituem essa arte tão nobre. Conhecer o mundo em que se vive e conseguir integrá-lo ao contexto durante a leitura é, sem dúvida, um desses fatores que auxilia o leitor a exercer seu papel.

Segundo Solé (1998, p.18):

Na leitura, o leitor é um sujeito ativo que processa o texto e the proporciona seus conhecimentos, experiências, e esquemas prévios. Parto da ideia de que o leitor especialista atribui sentido e significado ao texto e rejeito o pressuposto de que o recita (exceto quando a atividade da leitura corresponde a este objetivo: por exemplo, na declamação poética).

Nesse sentido, a relação entre quem lê o que é lido necessita de uma conexão direta e interativa que favoreça ao leitor meios de utilizar suas experiências culturais durante a leitura. Dessa maneira, Solé (1998, p.22) assinala que: "Leitura é um processo de interação entre o leitor e o texto".

Este estudo segue a concepção de leitura apresentada por Solé (1998). Trata-se da concepção na perspectiva interativa que enxerga a 
leitura como processo e o leitor como sujeito ativo que faz uso de suas expectativas e conhecimentos prévios. Nessa concepção, para ler é necessário ter habilidade para decodificar e dirimir ao texto os objetivos do leitor, suas ideias e experiências prévias (SOLÉ, 1998, p. 23). Dessa forma, entende-se que o ato de ler é, na sua essência, um processo muito dinâmico e, por isso, depende da interação entre 'leitor x texto' para evoluir. Toda bagagem cultural, toda experiência de vida, toda visão de mundo que o leitor traz consigo para esta ação colabora para o seu desenvolvimento, à medida que incorpora ao contexto fatos que o leitor já conhece.

Assevera-se que cabe ao professor estimular seus alunos/leitores a descobrirem, por meio da leitura, novos fatos e novas informações que o ajudem a evoluir cognitivamente. No entanto, antes de prosseguir é importante questionar: Como desenvolver a leitura com hipertexto digital?

No mundo contemporâneo, em que a cada instante algo novo é produzido e publicado na hipermídia, a vasta variedade de informações disponíveis nesse suporte obriga leitores a adaptarem-se a uma nova dinâmica ou a sucumbirem frente a sua ignorância. Em tal processo de adaptação inclui-se a produção e propagação de hipertextos. Nessa linha, Santaella (2007, p. 300) assinala que "o hipertexto passou, há alguns anos, a coabitar com os multmeios, misturas de sons, ruídos, imagens de todos os tipos, fixa e animadas, configurando os ambientes de hipermídia". Sendo assim, como o leitor pode se adaptar a essa nova realidade?

Há muito tempo, a história da humanidade vem sofrendo modificações que contribuem para a sua evolução, dando-Ihe condições para seu desenvolvimento enquanto sociedade organizada. Essas modificações também ocorrem com frequência no âmbito das linguagens, principalmente, nos meios de propagação de textos, o que exige que as pessoas estejam em constante adaptação.

Santaella (2007) orienta que o conceito de texto sofre transformações desde que as tecnologias entraram em uso. Nesse sentido, a autora relata que, com a invenção da fotografia no século XIX, as imagens passaram a povoar o mundo e, embora a produção de textos escritos tenha ocorrido em 
grandes quantidades no século XX, os meios de impressão não tinham como competir com o espetáculo proporcionado pelas imagens. Segundo a autora:

[...] no final do século XX, uma novidade surpreendente estava reservada para o texto escrito. Os processos de digitalização do computador absorveram-no, provocando sua migração para as telas dos monitores. Ao ser absorvido para este novo suporte, o texto passou por transformações, por verdadeiras mudanças de natureza na forma de hipertexto, isto é, de vínculos não lineares entre fragmentos textuais associativos, interligados por conexões conceituais (campos), indicativas (chaves), ou por metáforas visuais (ícones) que remetem, ao clicar deu botão, de um percurso de leitura a outro, em qualquer ponto da informação ou para diversas mensagens, em cascatas simultâneas e interconectadas (SANTAELLA, 2007, p. 299).

Nessa perspectiva, percebe-se a importância das imagens na transformação ocorrida no texto no final do século $X X$. O meio de propagação de informação e cultura, que até então tinha como detentor o livro impresso, passou por transformações promovidas pela digitalização ${ }^{3}$ dos textos. A título de exemplo, cita-se o projeto Gutemberg 4 , a partir do qual o texto exposto na tela dos computadores passou a invadir a sociedade como nova proposta para realização da arte de ler. Foi uma grande inovação que continua em constante evolução até hoje. Porém, é importante ressaltar que, embora o computador e a leitura mediada por ele estejam presentes no cotidiano de grande parte da população, isso ainda não chegou a sua totalidade. Em outras palavras, pode-se dizer que há uma enorme gama de pessoas sem condições de interagir com a máquina e com todos os recursos que ela pode oferecer.

A exclusão digital é um fato presente na sociedade contemporânea, que precisa ser modificada o mais breve possível. Por outro lado, ainda há

\footnotetext{
3 Consiste na transformação do texto impresso (forma analógica) no texto digital. Para Santaella (2007), [...] na digitalização, qualquer fonte de informação pode ser homogeneizada em cadeias sequências de 0 e 1 (binária), sendo suscetível de ser tratado por qualquer computador.

${ }_{4}^{4}$ Criado em 1971 por Michael Hart na Universidade de Illinois, o projeto Gutemberg tem como filosofia a disponibilização de informações, livros digitais e outras matérias gratuitamente para que as pessoas possam ler, usar, citar e pesquisar. O projeto está disponível para acesso em: <http://www.gutenberg.org/wiki/PT_Principal>
} 
pessoas que têm o acesso ao computador e seus recursos, mas não sabem ao certo como manuseá-la, fato que prejudica diretamente a realização de leitura nesta plataforma.

Almeida (2003, p.34) assinala que:

O leitor na web não lê da mesma forma que o leitor de livros ou revistas de papel. O leitor-navegador tem o mundo ao alcance do clique do mouse. Basta o texto tornar-se monótono para que o leitor dirija-se a outras paragens, provavelmente para nunca mais voltar.

Conforme o autor, não se associa ao leitor de textos impressos, isto é, aquele que usa o livro físico para ler, o mesmo comportamento daquele que usa o computador como veículo para leitura. As características inerentes ao texto digital necessitam que o "leitor-navegador" (ALMEIDA, 2003) detenha habilidades específicas para realizar essa ação. Não é fácil ler no ambiente virtual, pois ao mesmo tempo em que o leitor tem a sua inteira disposição um enorme legado de informações instantâneas, tem também muitas armadilhas que podem interromper ou adiar e até mesmo abandonar a prática da leitura. Esses leitores são chamados por Almeida (2003) de leitoresnavegadores. Segundo o autor: "Os leitores-navegadores refletem a diversidade do mundo real. Possuem formação e hábitos distintos, oriundos de ambientes culturais também distintos" (ALMEIDA, 2003, p. 35).

Desta maneira, entende-se que ler no ambiente virtual requer habilidades e atitudes diferentes por parte do leitor de texto impresso. Sabese também que muitos percalços podem estar à beira do caminho e atrapalhar a evolução da leitura, assim como também podem facilitar a vida do leitor por ter acesso instantâneo a uma enorme variedade de conteúdo disponível. Essas duas situações andam quase que em paralelo, sendo distinguidas por uma linha muito tênue que direciona o leitor para a evolução ou fracasso na leitura.

Diante disso, ressalta-se a importância da preparação técnica do leitor para atuar no ambiente virtual e aproveitar ao máximo os recursos que ele disponibiliza. Destaca-se na sequência a discussão dos resultados obtidos da primeira categoria. 


\section{NAVEGANDO POR CONEXÕES HIPERTEXTUAIS}

Dentre várias características que constituem o hipertexto digital, a conexão de textos por navegação com hiperlinks está sempre em destaque. A possibilidade de conectar vários textos com o uso de hiperlinks favorece a construção de pontes entre um texto e outro. Lévy (1998, p.20) assinala que os nós podem ser palavras, páginas, imagens, gráficos, sequências sonoras, e não são ligados linearmente. Essa falta de linearidade deixa o texto mais dinâmico, exigindo que o leitor seja mais dinâmico também. Nesse sentido, buscou-se conhecer a atitude do hiperleitor ao encontrar um hiperlink durante a leitura. Para tal, indagou-se: "O que você faz quando encontra um nó (hiperlink) no hipertexto?".

Gráfico 01 - Resultados sobre as atitudes dos alunos ao encontrar um hiperlink no hipertexto

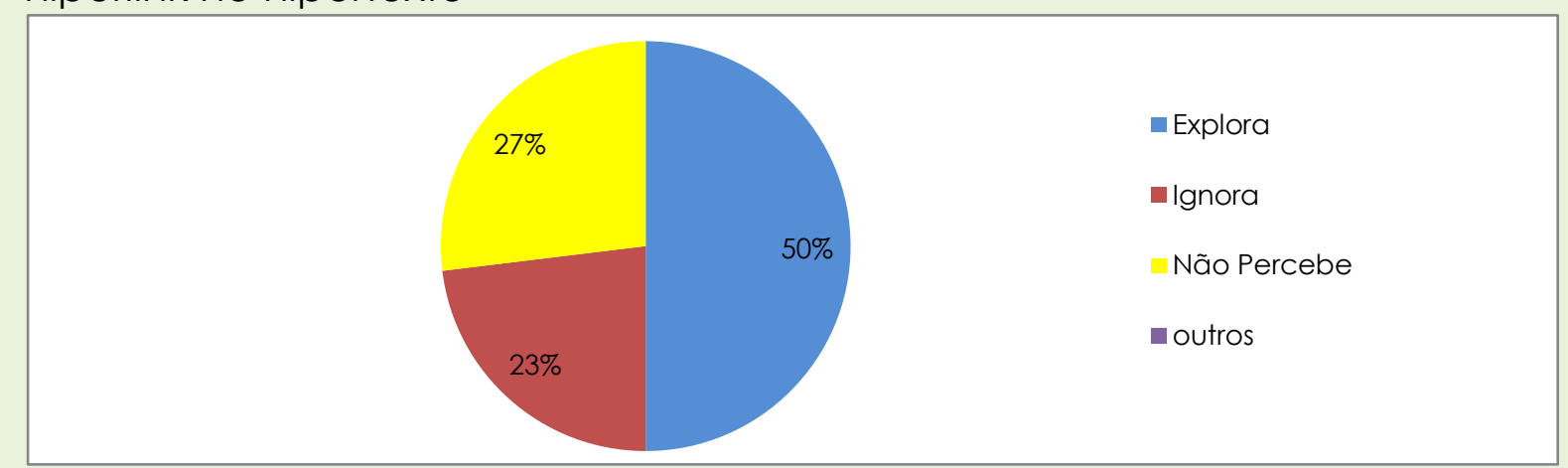

Fonte: Elaborado pelo autor, 2018.

Diante do referido questionamento, os alunos tiveram as seguintes opções de resposta: clicar no hiperlink para explorá-lo; ignorar e seguir a leitura do texto; geralmente não perceber o hiperlink; outra atitude. Dos alunos respondentes, $50 \%$ indicaram que clicam e exploram o conteúdo de cada hiperlink que aprece no hipertexto. Essa é a atitude esperada para leitores de hipertextos. Koch (2007, p. 27) orienta que "os links funcionam, portanto, como portas de entrada para outros espaços, visto que remetem o leitor a outros textos virtuais que vão incrementar a leitura".

Nesse sentido, a proposta é que o hiperleitor possa, a cada click, ampliar seus horizontes durante a leitura, tendo acesso a outros textos que podem complementar o conteúdo que já está sendo lido. 
Dentre os alunos respondentes, $23 \%$ referiram que localizaram o hiperlink, mas preferiram não acessá-lo por algum motivo particular. Atitude diferenciada do restante dos alunos que totalizou $27 \%$ que não acessaram o hiperlink por não ter percebido a sua presença no hipertexto. Somando-se estes percentuais mencionados, observou-se que $50 \%$ dos alunos não realizaram a leitura do hipertexto acessando hiperlinks. Sobre esse fato, Koch (2007) citando Storrer (2000), esclarece que a forma não linear (com hiperlinks) de organização do texto favorece que a leitura seja seletiva por grupos heterogêneos de receptores, sendo que cada receptor decide de acordo com seus conhecimentos, interesses e preferências.

Em assonância com o pensamento de Storrer (2000) e de Koch (2007), entende-se que a atitude tomada pelos $50 \%$ dos alunos que não acessaram os hiperlinks não se constitui um erro, pois é o hiperleitor quem decide o que vai ler e como vai ler, decide que caminho vai percorrer, se vai ou não abrir um hiperlink. É ele quem decide quais são suas preferências e prioridades.

Hissa (2009) concebe "o link como o elemento essencial para que todo o processo de associação das informações e conteúdos presentes no hipertexto seja capaz de acontecer". Dessa maneira, entende-se que abrir o hiperlink e acessar outros textos complementares é essencial para que a proposta de leitura com um hipertexto digital seja realizada.

Embora o hiperleitor tenha autonomia para decidir seus percursos, não acessar um link pode, em alguns momentos, prejudicar a compreensão global do hipertexto. Koch (2007) assevera que o hiperleitor pode seguir por outros caminhos que não sejam via hiperlinks, porém, reforça o pensamento de Storrer (2000) que orienta que não seguir os caminhos planejados pelo autor do hipertexto pode gerar consequências na produção do texto e da coerência.

Durante as observações sistemáticas, notou-se que os alunos estavam mais propensos a continuar as leituras do hipertexto em função da variedade de informações que estavam atreladas ao texto principal. A transitividade entre um texto e outro associado à visualização das imagens disponibilizadas colaborou positivamente para isto. Quando questionados 
sobre a sua maneira de ler o hipertexto digital, os alunos investigados responderam da seguinte maneira (Gráfico 02):

Gráfico 02 - Resultado da definição dos alunos sobre a maneira de ler o hipertexto digital

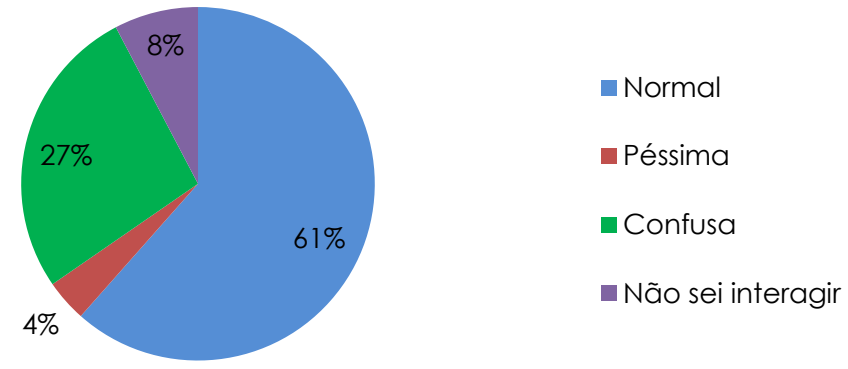

Fonte: Elaborado pelo autor, 2018.

A opção "Normal - Tenho facilidade em ler esse tipo de texto" foi assinalada por $61 \%$ dos investigados. Dessa maneira, compreende-se que, para esses alunos, acessar outros textos por meio dos hiperlinks não demonstra nenhum entrave. Para eles, a ação de abrir um hiperlink e transitar repetidas vezes por outros textos é até considerada fácil. Apenas $4 \%$ consideram que têm dificuldade em ler um hipertexto e $8 \%$ não sabem interagir de nenhuma forma com o hipertexto.

Hissa (2009), citando Codina (2000), alega que, como a estrutura do hipertexto organiza as informações em redes unidas por relações, essa forma multisequencial de apresentar as informações pode causar sobrecarga e desorientação se os caminhos percorridos até o texto forem múltiplos.

Diante do exposto pelos autores e pela observação sistemática durante as aulas, acredita-se que realmente foi por esse motivo que um total de $12 \%$ dos respondentes alegou ter dificuldades ou não saber interagir com um hipertexto. Por outro lado, indaga-se, neste momento, se os $61 \%$ que assinalaram a opção "Normal - Tenho facilidade em ler esse tipo de texto" conseguiram transpor um texto após o outro e envolver-se na formação de sentido nesta leitura. Koch (2007) assevera que cabe ao hiperleitor, por meio dos acessos aos links, detectar as informações relevantes para uma progressão textual coerente. Nesse sentido, entende-se que acessar um link 
é importante e pode facilitar a construção de sentido, visto que o autor do texto elabora e disponibiliza as informações em uma teia com palavraschave justamente para que seus leitores possam percorrê-la. É nessa conectividade de um texto ao outro por meio dos hiperlinks que o leitor vai estruturar a sua construção de sentido. Conforme Marcuschi (1999, p.30), "a leitura do hipertexto é como uma viagem por trilhas. Ela nos obriga a conectar nós para formar redes de sentido".

\section{A Webquest "Eleições 2018 - Um Maranhão melhor para todos" em foco}

Eleições 2018 - Um Maranhão para todos, trata-se de uma Webquest disponibilizada na internet, que foi construída pelo pesquisador, e que teve como tema as eleições para o Governo do Estado do Maranhão em 2018.

Neste estudo, compreende-se que leitura hipertextual digital requer habilidade e motivação, tanto quanto os textos impressos. Talvez, essa motivação possa ser proporcionada com atividades dinâmicas e desafiadoras. Para o leitor de hipertextos digitais, $\bigcirc$ emprego da metodologia Webquest suscita uma possibilidade de evitar dispersão e fomenta a concretização da leitura pela dinâmica que esta ferramenta proporciona. Segundo Abar e Barbosa (2008), ao utilizar uma Webquest, o desafio para o leitor é criar um ambiente em que ele possa descobrir potencialidade, adquirir autonomia, responsabilidade, disciplina, respeito aos outros e autoconfiança.

Dodge (1999), criador da ferramenta, define-a como uma atividade investigativa que usa a internet e seus recursos como suporte para interação dos alunos na busca de informações. Outros estudiosos do assunto também expuseram suas definições em relação à ferramenta. Abar e Barbosa (2008, p.11), ao definirem Webquest, afirmam que "É uma atividade didática, estruturada de forma que os alunos se envolvam no desenvolvimento de uma tarefa de investigação usando os recursos da internet". Baseado em tais ponderações preliminares, a primeira indagação que se aponta sobre a temática é: De onde vem essa ferramenta? 
Encontra-se em Bottentuit Jr e Coutinho (2008, p.01) a seguinte informação:

As WQ's surgem, no ano de 1995, pela mão dos seus mentores Tom March e Bernie Dodge da Universidade de San Diego na Califórnia que as desenvolvem no âmbito das atividades propostas na disciplina EDTEC 596, "Interdisciplinary Teaching with Technology". A palavra Webquest, em sua etimologia, remete-nos para a soma de duas palavras, ou seja, web (rede de hiperligações) e quest (questionamento, busca ou pesquisa).

A Webquest foi desenvolvida a partir de um modelo de atividade criado para resolução de um problema real da época, em que os alunos tiveram a tarefa de redigir um documento para o diretor da escola, recomendando ou não o uso de um software (ABAR; BARBOSA, 2008).

Hoje, as Webquests constituem-se em uma ferramenta de investigação orientada na internet, sendo que todo conteúdo a ser investigado deve ser previamente planejado, elaborado e analisado pelo professor/mediador. Dessa forma, está se garantindo que o aluno tenha acesso a conteúdos originais e de qualidade, visto que qualquer pessoa pode postar informações no ambiente virtual, mas nem tudo pode ser aproveitado para o ensino. Em sua composição estrutural, encontram-se seis partes que, juntas, compõem uma Webquest (ABAR; BARBOSA, 2008). São elas:

1. Introdução - Nesta secção, o assunto da WQ é apresentado brevemente e deve-se propor os questionamentos que vão direcionar a investigação;

2. Tarefa - Aqui temos que pôr em prática as ações da WQ. A tarefa deve propor a atividade que será planejada e executada de maneira clara, objetiva e principalmente criativa. É importante que seja proposto algo que motive e desafie o aluno. A atividade final deverá ser apresentada as outras pessoas da turma ou da comunidade.

3. Processo e Recurso - Agora, o aluno será direcionado ao conteúdo de investigação que irá realizar e localizar as informações necessárias todo na internet. Para isso o professor/mediador irá disponibilizar links e/ ou hiperlinks previamente selecionados. O recurso utilizado para esta ação será o computador com acesso à internet. O processo nesta dinâmica consiste na orientação de como o aluno necessita fazer para logra êxito na atividade.

4. Avaliação - Esta secção é essencial a WQ. O aluno precisa saber em detalhes como será avaliado, quais serão os critérios adotados, a forma de avaliação (individual ou em grupo). Cada secção deverá ser avaliada e o professor deve oportunizar meios para que o aluno possa identificar se houve sucesso e melhorar seu desempenho. 
5. Conclusão - O aluno irá fazer uma análise geral da atividade e destacar alguns pontos específicos durante o desenvolvimento. Por exemplo, deve ser objetiva e muito clara, indicar os pontos interessantes, relatar a importância e relevância do tema, e tentar propor novos questionamentos para futuras investigações.

6. Créditos - Aqui, todos os materiais usados na preparação e construção da WQ serão listados. A escola, os autores e os sites de construção também deverão estar nesta secção com nome, e-mail e o público alvo.

A opção pelo uso de Webquest se dá em função da motivação que proporciona no usuário e em razão da utilização de um espaço para o exercício da criatividade. Bottentuit Jr e Coutinho (2008, p. 01) destacam que: "As Webquests constituem uma forma de ensinar os professores a utilizar a Internet com criatividade e consciência". Sendo assim, motivação e criatividade são dois recursos essenciais à realização de qualquer atividade que esteja no âmbito escolar, inclusive a leitura. A ferramenta metodológica Webquest pode proporcionar tais elementos aos leitores quando empregada com técnica. A partir dessa perspectiva, deseja-se destacar a sua utilização de maneira que proporcione ao leitor vantagens que oportunizem melhorias na concentração durante a prática de leitura.

Além disso, a referida ferramenta apresenta, em sua estrutura e organização, características discursivas muito relevantes para este estudo, pois ela parte do pressuposto de que o aluno-leitor busca constantemente informações e sente-se motivado a novas descobertas quando desafiado.

Moran (1997) já alertava para as transformações que o ensino iria sofrer a partir da inclusão da tecnologia na sala de aula. O acesso à internet como fonte de pesquisa e de auxilio dos professores na execução das atividades constitui-se em um potencial de transformação no modo de aprender. Nesse sentido, o autor menciona que:

A Internet é uma tecnologia que facilita a motivação dos alunos, pela novidade e pelas possibilidades inesgotáveis de pesquisa que oferece. Essa motivação aumenta se o professor a faz em um clima de confiança, de abertura, de cordialidade com os alunos. Mais que a tecnologia, o que facilita o processo de ensino-aprendizagem é a capacidade de comunicação autêntica do professor, de estabelecer relações de confiança com os seus alunos, pelo equilíbrio, competência e simpatia com o que atua (MORAN, 1997, texto digital). 
Sendo assim, cabe ao docente conduzir a aula com a preocupação de saber orientar os alunos para o uso adequado das tecnologias, buscando melhorar as condições de aprendizagem. Para isso, é importante ressaltar a necessidade de trabalhar num clima amistoso de interação tanto entre os pares, como também entre os indivíduos e as ferramentas tecnológicas.

Dessa maneira, é inerente ao docente planejar previamente suas aulas, baseando-se em estratégias de ensino que possam oportunizar atividades variadas e desafiadoras em vários níveis de dificuldade, que favoreçam a reflexão na esfera discursiva dos gêneros. A interação com a ferramenta Webquest precisa ser mediada pelo docente, o qual deve planejar e criar a Webquest. Para que o êxito seja alcançado a contento das partes envolvidas, não basta apenas colocar o aluno em frente a uma máquina conectada à internet e deixá-lo solto, à deriva. A atividade deve ser direcionada pelo professor até que o aluno sinta-se seguro do que está fazendo e tenha a consciência dos procedimentos técnicos que devam ser adotados.

Para Bottentuit Jr e Coutinho (2008 p.02),

Geralmente as WQ's tentam envolver seus alunos com grande quantidade e variedade de informações e tecnologias para que a partir daí eles possam aprender de forma mais autónoma, sem necessidade da intervenção directa do professor e respeitando a nova filosofia educacional, onde o aluno é responsável pelas suas aprendizagens, e o professor é apenas o gestor dos caminhos por onde o aluno percorre para atingir o conhecimento.

O emprego da Webquest na circunstância citada pelos autores é ideal, pois possibilita motivar e fortalecer cognitivamente e culturalmente 0 hiperleitor que, além de levar informação original, proporciona momentos de reflexão e pensamentos críticos a respeito do conteúdo lido. A ausência dessa reflexão no cotidiano escolar do aluno-leitor pode interferir na formação da cidadania de um leitor que não interage criticamente frente às informações provenientes dos meios de comunicação.

Nesse contexto, esboça-se imensa preocupação com o leitor que não compreende o que lê nos variados gêneros e meios de comunicação, visto 
que seu próprio crescimento está sendo prejudicado. É necessário ter em mente os objetivos oferecidos pela ferramenta e saber como ela pode ajudar a modificar essa triste realidade.

Bottentuit Jr (2010, p. 6) esclarece que:

[...] a pesquisa deve possibilitar ao aluno oportunidade para que elabore as suas próprias hipóteses e teorias, para que recrie seus próprios conceitos com base no questionamento do problema que se apresenta e, nesse sentido, a pesquisa somente poderá ser considerada na sua plenitude se conseguir levar 0 aluno a desenvolver capacidades cognitivas ao nível da análise, síntese e avaliação. Da mesma forma, o principal objetivo de uma Webquest enquanto estratégia de pesquisa orientada é que seja capaz de proporcionar uma "aprendizagem ativa", ou seja, conseguir que os alunos transformem e assimilem os conhecimentos que já têm em estruturas de conhecimentos mais complexas e elaboradas.

O autor retrata a ideia de que o aluno é protagonista da construção de seu próprio conhecimento. É ele que interage na internet, adquire e troca informações com seus colegas e agrega um sentido ao que está descobrindo. Em alguns casos, ele já possui a informação, mas precisa de subsídios que possam transformá-la em algo a ser analisado e, a partir disso, gerar uma síntese, um entendimento. O uso de Webquest não deve ser visto apenas como motivação, pois este não é o seu foco principal. A atividade precisa ser desafiadora, de modo que o aluno busque uma solução exequível para o problema apresentado.

Agora que se tem uma visão geral sobre a ferramenta Webquest, é possível compreender melhor a sua dinâmica e entender a análise dos resultados emergentes da segunda categoria obtida.

Inicialmente, na pesquisa, houve a necessidade de saber se os alunos investigados já tinham conhecimento ou se já tinham ouvido falar em Webquest antes de participarem das atividades da pesquisa. Constatou-se que $19 \%$ dos alunos já conheciam a ferramenta, e que a grande maioria da turma, isto é, $81 \%$ dos investigados não conheciam e nem tinham ouvido falar em Webquest.

Assim, evidenciou-se uma ferramenta metodológica nova para grande parte do grupo. Esse dado gerou desconfianças no pesquisador sobre a 
eficiência da utilização da ferramenta com alunos que não a conheciam, pois se entende que "em um ambiente de aprendizagem, a situação inicial é constituída pelo que o aluno sabe, do que é capaz o que pode fazer e o que quer aprender" (ABAR; BARBOSA, 2008, p.12). Nesse sentido, no primeiro encontro com a turma, optou-se por executar uma minioficina didática sobre Webquest, na intenção de colocar o grupo de alunos a par da composição estrutural, objetivos e funcionalidades da ferramenta.

Logo em seguida a execução da Webquest pelos alunos, surgiu a necessidade de saber seus posicionamentos a cerca dos aspectos que envolvem o uso da ferramenta com a leitura de hipertextos digitais. Para isso, perguntou-se: "A ferramenta Webquest facilita a leitura?".

Gráfico 03 - Respostas dos alunos sobre leitura de hipertextos por intermédio de uma Webquest

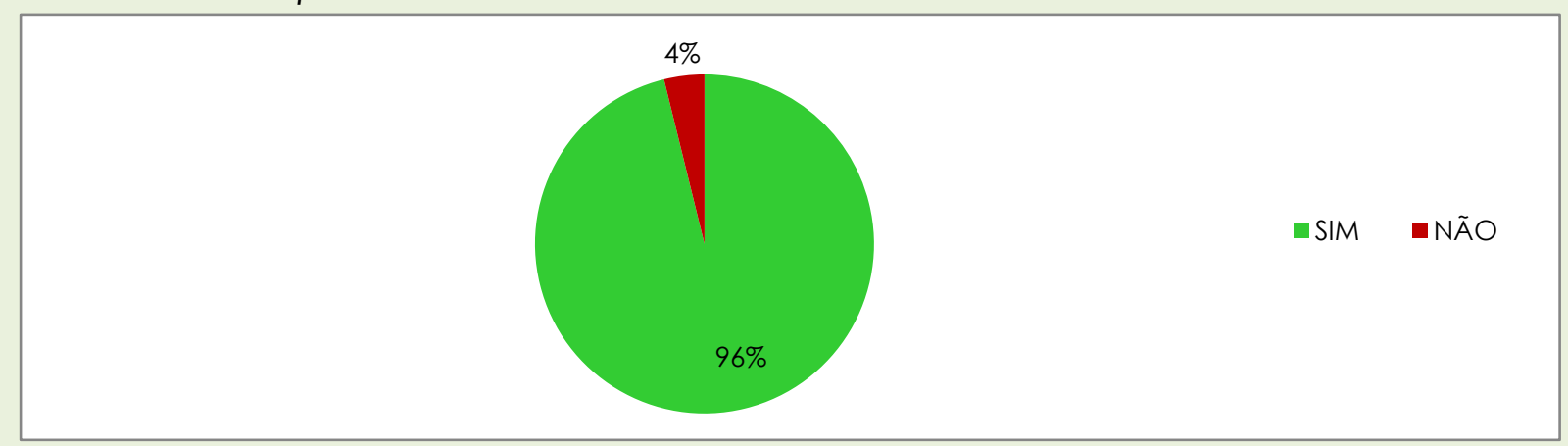

Fonte: Elaborado pelo autor, 2018.

No Gráfico 03, percebe-se que um número expressivo, isto é, $96 \%$ dos investigados, assinalaram a opção "Sim". Isso retrata que a Webquest facilitou a leitura dos hipertextos. Acredita-se que essa facilidade tenha sido considerada em função da ferramenta organizar e disponibilizar as zonas que deveriam ser pesquisadas. Com isso, evitou-se que os alunos tivessem que gastar mais tempo procurando por sites que contemplassem seus objetivos, gerando certa comodidade na busca. Na sequência, são apresentados alguns relatos de alunos, que auxiliam a compreender esse resultado:

[A24] Sim, porque vai direto no assunto que você quer. 
[A23] Sim, porque tem todos os assuntos organizados.

[A05] Sim, pois o leitor não vai ter o trabalho de abrir outras páginas para pesquisar.

[A22] Sim, pois facilita as atividades em grupo.

[A16] Sim, pois cria a curiosidade.

[A25] porque é usado na atividade que desperta interesse e motiva na leitura.

[A21] Sim. Porque facilita a compreensão do texto.

[A19] Sim, pois facilita tanto na leitura quanto na compreensão.

[A17] Sim, pois facilita o entendimento da leitura e a sua interpretação.

[A4] Sim, por que ela simplifica tornando melhor o compreendimento.

[A3] Sim, porque ela facilita a compreensão de cada texto.

[A20] Não, é muito embaraçado. Não consigo entender muito bem.

Para os alunos, o fato de os links do material necessário para leitura já estarem pré-selecionados e disponíveis em um ambiente virtual de fácil acesso como a Webquest, possibilitou que a leitura fluísse mais rápido, gerando a sensação de facilidade. Durante as observações sistemáticas, constatou-se que, se esses alunos não estivessem conseguindo compreender as leituras, o produto final que lhes foi proposto entregar em um curto espaço de tempo não seria concluído por falta de informação. Na dinâmica dessa ferramenta, se o leitor não entende os textos, ele também não avança na atividade, conforme foi destacado pelo aluno A20, único a assinalar a opção "não". Para esse aluno, a ferramenta não facilita a leitura, pois ele embaraçou-se com os textos e, consequentemente, não entendeu muito bem.

De fato, é necessária uma mudança de postura na prática da leitura hipertextual digital. Caso contrário, o processo de ler torna-se um entrave, visto que o leitor não avança na leitura. Rojo (2013) reforça que os textos da contemporaneidade mudaram a postura do leitor. Assim, as competências usadas para prática da leitura hipertextual precisam estar atualizadas e 
sintonizadas com as diversas formas que compõem os textos da hipermídia, uma vez que o leitor é protagonista do ato de ler. Dessa forma, na hipertextualidade, sua postura não pode permanecer a mesma do passado.

Vários fatores poderiam ser elencados como empecilhos para o aluno A20 não ter conseguido interagir com o hipertexto e, consequentemente, não seguir adiante na leitura. Talvez, até a falta de experiência com o manuseio do computador, por exemplo, pode ter atrapalhado. Este fato reforça a necessidade das escolas iniciarem o mais breve possível o letramento digital com seus alunos, na intenção de proporciona-lhes meios de interagir com as tecnologias com mais segurança, habilidade e fluidez. A interação com as variadas tecnologias e seus recursos é um fator importante para vida na sociedade contemporânea. Não se deve simplesmente absterse dos avanços tecnológicos e caminhar em sentido contrário.

Quando questionados se consideravam uma desvantagem usar Webquests com hipertextos, $81 \%$ dos alunos responderam que "não", $15 \%$ que "sim" e $4 \%$ assinalaram "talvez".

[A18] Não, porque é prática e fácil de fazer.

[A2] Não, é uma vantagem pela praticidade do desenvolvimento da leitura.

[A6] Não, porque ela facilita as dificuldades para quem tem bastante.

[A16] Não. É uma nova forma de conhecimento com mais informações.

[A15] Não, Webquest auxilia a leitura.

[A18] Não, pois nela obtemos mais informações que não sabíamos.

[A1] Não acho, pois é fundamental nos dias de hoje.

Como se pode perceber nas respostas dos alunos à questão, a praticidade foi destacada mais uma vez. Dessa forma, entende-se que a organização da ferramenta agradou os leitores que viram na situação uma oportunidade de ganhar tempo e ler mais rápido. Com base nos relatos de A6, A16, A18, infere-se que esses alunos sentem dificuldades em navegar 
aleatoriamente na internet, isto é, não têm facilidade em localizar sites que Ihes deem a informação que estão procurando.

Este estudo baseou-se nas ideias de Dodge (2002) ao orientar que Webquests suscitam interesse porque organizam e orientam o trabalho de estudantes e professores. Dessa maneira, esperava-se que $\circ$ uso da ferramenta Webquest disciplinasse a interação com o ambiente digital e tentasse evitar a dispersão do leitor e o abandono da leitura na internet. Almejou-se que a forma estrutural de uma Webquest contribuísse para manter o leitor focado em concluir a tarefa o mais breve possível. Assim, questionou-se: $O$ uso da ferramenta Webquest colabora para que você não se disperse ao ler na internet?

Gráfico 04 - Respostas sobre o uso de Webquest e dispersão na internet

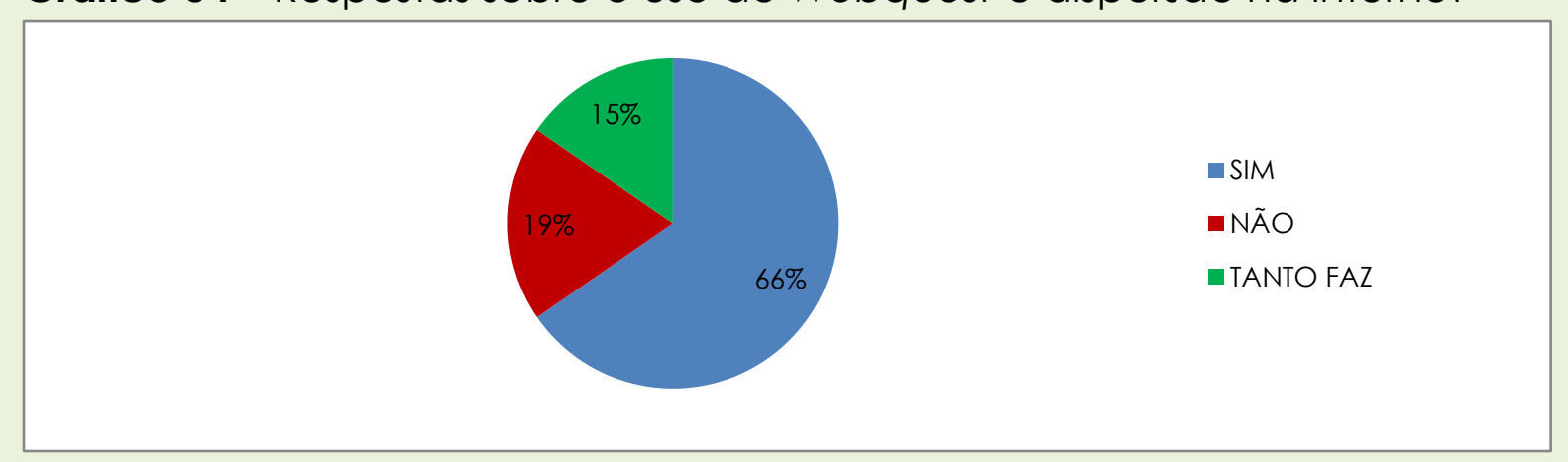

Fonte: Elaborado pelo autor, 2018.

Com os resultados do Gráfico 04, constatou-se que $66 \%$ dos investigados indicaram que a ferramenta Webquest colabora para a não dispersão no mar de informações existentes na internet. Esse número, que se encontra acima da metade, já justifica o uso da ferramenta Webquest com atividades na internet em parceria com hipertextos digitais. É muito comum leitores inexperientes, ao acessarem a internet, dispersarem rapidamente e não conseguirem retomar o foco inicial traçado antes da leitura.

Nas observações sistemáticas, o pesquisador percebeu que os grupos estavam bastante motivados em concluir a atividade proposta. Trabalhavam com afinco e foco nos textos. Porém, alguns alunos não conseguiram realizar a atividade seguindo os procedimentos indicados na 
Webquest. Eles tiveram problemas na execução da tarefa, pois não acessaram os hiperlinks e, consequentemente, não realizaram as leituras dos demais textos inseridos no hipertexto principal. Dessa maneira, a colaboração com informações para o grupo foi aquém da esperada. Entretanto, ainda assim não acessaram sites alheios à temática da atividade, principalmente sites de redes sociais.

Para se ter uma visão global das percepções dos alunos acerca do uso da ferramenta metodológica Webquest com leitura de hipertextos digitais, questionou-se aos alunos como analisariam a utilização da Webquest como ferramenta de desenvolvimento da leitura. As respostas estão representadas no Gráfico 05, a seguir.

Gráfico 05 - A utilização de uma Webquest no desenvolvimento da leitura

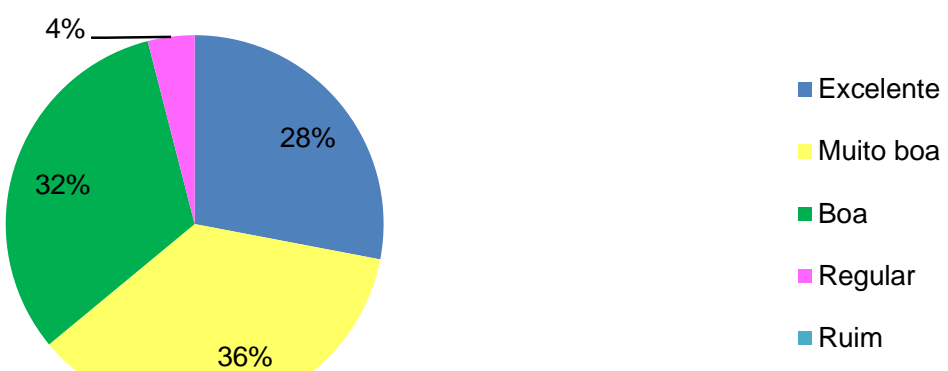

Fonte: Elaborado pelo autor, 2018.

No gráfico anterior, observa-se que $28 \%$ dos alunos consideraram essa contribuição "Excelente"; $36 \%$ indicaram ser "Muito boa"; $32 \%$ consideram "Boa; e apenas $4 \%$ dos alunos indicaram a opção "regular". Com base nesses dados, percebe-se a aprovação da ferramenta pelos alunos investigados. Alguns alunos, ao justificarem suas respostas, disseram:

[A7] porque a gente aprende de forma criativa.

[A11] porque é uma excelente ferramenta para desenvolver melhor o aprendizado.

[A13] porque é uma maneira prática de se aprofundar mais sobre $\mathrm{o}$ assunto.

[A15] A utilização da Webquest desenvolve uma melhor compreensão. 
[A18] porque nela temos imagens e várias informações que nos ajuda a ler melhor e nos focar também.

[A26] Motiva o aluno, pois facilita a leitura do mesmo.

[A10] Nem toda as pessoas gostam de ler pela internet.

Nos relatos, observou-se que alguns termos como "criatividade", "facilidade" e "praticidade" representaram o que de fato levou esses alunos a aprovarem o uso da ferramenta. Neste estudo, não se buscou a aprovação dos investigados, mas sim, conhecer como estes leitores utilizam a ferramenta em benéfico próprio e também da coletividade, tornando o ato de ler mais interessante em função da motivação proporcionada pela ferramenta Webquest. Nesse viés, Dodge (2002) orienta que a Webquest foi planejada para que os alunos se concentrassem não só no uso das informações, como também em desenvolver o pensamento nos níveis de análise, síntese e avaliação.

Sendo assim, não se trata de uma simples busca na internet, mas de uma metodologia organizada de pesquisa que pode, além de dar condições para o desenvolvimento das informações obtidas a partir da busca, motivar os alunos a continuar na atividade de leitura.

Por fim, surgiu a necessidade de saber a avaliação dos alunos sobre a atividade com Webquest, na intenção de conhecer suas satisfações e/ou frustações durante o uso. Nesse sentido, inquiriu-se: Como você considera o resultado final da sua atividade com esta ferramenta?

Gráfico 06 - Resultados da avaliação final feita pelos alunos sobre a ferramenta Webquest

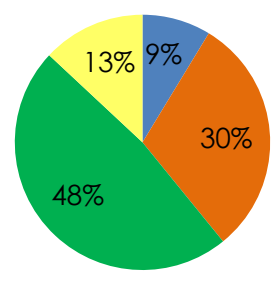

$$
\begin{aligned}
& \text { Excelente } \\
& \text { Muito boa } \\
& \text { Boa } \\
& \text { Regular } \\
& \text { Ruim }
\end{aligned}
$$

Fonte: Elaborado pelo autor, 2018. 
No Gráfico 06, as opções "Excelente" com 9\%, "Muito boa" com 30\% e "Boa" com 48\%, quando somadas, totalizam $87 \%$ das indicações dos investigados. Isso demonstra que a avaliação feita pelos alunos sobre o uso da ferramenta Webquest foi positiva, fato relevante e condizente com o resultado almejado pelo pesquisador.

Alguns alunos expressaram o seguinte:

[A25] Porque não era som mais uma aula comum e chata como todas as outras, mas procurávamos retirar informações de outras fontes.

[A18] Pois antes para me ler assuntos grandes era muito ruim, não me chamava atenção.

[A7] porque com isso a gente adquiriu conhecimento.

[A26] Tive algumas dificuldades mas fluiu bem mais.

Desataca-se o relato do aluno A25 que, ao comparar a aula em que se fez uso da ferramenta com outras aulas em que ela não foi utilizada, retrata sua satisfação, valorizando a motivação que seu uso the trouxe. Tal fato também foi destacado pelo aluno A18.

O trabalho em regime de cooperação também serviu como fonte de motivação para a realização da atividade. Nas observações sistemáticas, notou-se a empolgação dos alunos não só em discutir e compartilhar informações encontradas nas leituras, como também em perceberem que, ao acessar um hiperlink, ele era direcionado para uma página com a informação que ele buscava. Alguns alunos, inclusive, chegaram a comemorar em voz alta a descoberta. Esse fato gerou um clima competitivo produtivo, visto que todos os envolvidos na atividade buscavam ler e encontrar logo as informações no intuito de serem os primeiros a compartilhar o feito.

$\mathrm{Na}$ aprendizagem cooperativa, essa interação entre os alunos faz com que eles se envolvessem ativamente com o objetivo proposto para leitura, o que deve acontecer num ambiente amistoso. Nesse sentido, Abar e Barbosa 
(2008, p.82) orientam que "além da interação e colaboração, deve haver uma relação de respeito mútuo entre os componentes do grupo, ações conjuntas e, principalmente, interdependência positiva". Essa interdependência positiva é um ponto forte na atividade, pois possibilita ao aluno ser responsável pela própria aprendizagem.

A intenção ao propor o emprego de uma Webquest para leitura de hipertextos digitais era também promover meios de organizar a pesquisa na internet, de modo que o leitor pudesse ter mais tempo para planejar as ações que iria seguir, bem como fomentar o trabalho em colaboração, a análise das informações obtidas e a discussão e socialização dos resultados com os colegas. Dessa forma, esperava-se que o resultado final da atividade perante os investigados fosse positivo e satisfatório para todos, o que de fato se concretizou.

\section{CONSIDERAÇÕES FINAIS}

É notória a presença de aparelhos eletrônicos nas salas de aula. São notórias também as mudanças que a utilização destes aparelhos tem feito na comunidade discente. Contudo, acessar a internet e realizar uma pesquisa simples ou ler um texto por completo tem sido uma tarefa muito complicada para alguns alunos. Assim, nota-se que a enorme variedade de informações existentes nas plataformas online, tanto ajudam quanto prejudicam o desenvolvimento cognitivo de alguns alunos.

Nesse sentido, o principal objetivo desta pesquisa foi averiguar as percepções dos alunos sobre o uso da ferramenta metodológica Webquest no desenvolvimento da leitura de hipertexto digital.

Diante da análise dos dados e resultados encontrados, constatou-se o potencial da Webquest para o desenvolvimento da leitura. Todavia, é importante ressaltar que aqui o foco principal não foi à compreensão leitora, mas sim o desenvolvimento da leitura hipertextual digital. Sendo assim, inferese que essa ferramenta foi capaz de modificar uma realidade antiga e constante na sala de aula durante as atividades que envolviam a leitura na internet: a dispersão e o abandono da leitura. 
O estudo comprovou como uma Webquest pode contribuir com o desenvolvimento da leitura hipertextual com alunos do Ensino Médio. Nessa perspectiva, destacou-se: a valorização da leitura na internet mediada por Webquest; a eficiência do trabalho em grupo em regime de colaboração; a empolgação na realização das tarefas demonstrando que os alunos estavam bastante motivados; a participação ativa e tomada de decisões antes e durante as reuniões para socialização das informações encontradas; o respeito pelo trabalho e opinião dos colegas nas discussões coletivas; a concentração e foco no objetivo proposto; a realização do trabalho de autoria e a aceitação por uma dinâmica pedagógica que favorecesse a autoaprendizagem.

Outra contribuição positiva para a ferramenta diz respeito à maneira como ela evitou que o aluno se dispersasse para outras páginas. O texto das seções Introdução e Tarefa fez com que os alunos tivessem curiosidade e ambição pela descoberta. A cada hiperlink que ele acessava esse interesse em prosseguir aumentava, pois o texto seguinte foi construído à luz dos processos semióticos, isto é, a integração de áudio, vídeo, fotos auxiliou na complementação do texto principal. Essa diversidade de meios de propagar a informação conquistou a atenção dos leitores, evitando que eles fugissem para outras páginas com outros conteúdos alheios ao que estavam lendo.

Os alunos também avaliaram positivamente $O$ uso da ferramenta Webquest no desenvolvimento da leitura. Segundo eles, Webquest proporciona uma forma criativa de aprender, pois favorece 0 aprofundamento no assunto e é uma excelente ferramenta para desenvolver o aprendizado.

Portanto, os resultados deste estudo demonstram que é viável melhorar os procedimentos antes e durante a leitura de hipertextos digitais com a ferramenta Webquest. Nesse sentido, apontam para a necessidade de aprofundar os estudos sobre Webquest e conhecê-la em outras perspectivas que favoreçam $\circ$ desenvolvimento do ensino, 0 desenvolvimento da leitura e o crescimento cognitivo do leitor. 


\section{REFERÊNCIAS}

ABAR, C.A.A.P.; BARBOSA, L.M. Webquest um desafio para o professor: uma solução inteligente para o uso da internet. 1. ed. São Paulo: Avercamp, 2008. $100 \mathrm{p}$.

ALMEIDA, R.Q. O leitor navegador (I e II). In: SILVA, E.T. (coord.). A leitura nos oceanos da internet. São Paulo: Cortez, 2003.

BARATO, J.N. Um jeito novo, simples e moderno de educar. Rio de Janeiro, ed. Zahar: 2004.

BARDIN, L. Análise de conteúdo.1.ed. São Paulo: Edições 70, 2011.280 p.

BOTTENTUIT Jr, J. B.; COUTINHO, C. P. Um Estudo com Autores de Webquests em Língua Portuguesa: avaliação do processo de concepção, utilização e resultados obtidos. 2008. 6 f. In: IX Congresso Iberoamericano de Informática Educativa, Caracas: Rede Iberoamericana de Informática Educativa (RIBIE). Disponível em: < http://hdl.handle.net/1822/7771 > Acesso em: 17 jan. 2017.

BOTTENTUIT Jr, J. B..Concepção, Avaliação e Dinamização de um Portal Educacional de Webquests em Língua Portuguesa. 637 f. Tese (Doutorado em Ciências da Educação) - Universidade do Minho: Braga:2010. Disponível em: < http://hdl. handle.net/1822/11889 > Acesso em: 17 jan. 2017.

CARVALHOJr, J.R. WEBQUEST: PercepçÕes sobre uma ferramenta metodológica de ensino no desenvolvimento da leitura hipertextual digital. Dissertação (Mestrado Acadêmico em Ensino) - Universidade do Vale doTaquari - UNIVATES, Lajeado: 2018.

CODINA,L. El libro digital y la wWw. $1^{a}$ Edición, Madrid: Ed. Tauro Producciones, Colección: Comunicación y Lenguajes. 2000.

DIESEL, A. Estratégias de compreensão leitora: uma proposta de atividades desenvolvidas sob a perspectiva das metodologias ativas de ensino. Dissertação (Mestrado em Ensino) - Centro Universitário Vale do Taquari UNIVATES, Lajeado: 2016. Disponível em: http://hdl.handle.net/ 10737/1198 acesso em: 03 jan 2016.

DODGE, B. Algumas ideias sobre Webquests. San Diego State University, 1999, Disponível em: < http://clickeaprenda.uol.com.br/sg/uploads/ User Files/File/algumas_ideias_sobre_WabQuest.pdf > Acesso em: 17 jan. 2017.

DODGE, B. Cinco Reglas para Escribir una fabulosa Webquest. Eduteka, 2002. Disponível em: <http://www.eduteka.org/Profesor10.php>. Acesso em: 16 out. 2017. 
GUEDES, T.A; ACORSI, C.R.L; MARTINS, A.T; JANEIRO, V.. Estatística desritiva. Projeto de ensino-aprender fazendo estatística. 2005. Disponível em:< https://www.ime.usp.br/ rvi cente/Guedes_etal_Estatistica_Descritiva.pdf>. Acesso em: 10 set. 2017

HISSA, D.L.A: A organização das informações em portais educacionais a partir de seus links: uma descrição comparativa dos portais centro virtual Cervan tes e Educarede. Dissertação (Mestrado em Linguística Aplicada) Univer sidade Estadual do Ceará. Fortaleza, 2009. Disponível em:< http://www . Uece .br/posla/dmdocuments/deboraliberatoarrudahissa.pdf> Acesso em: 26 mar. 2016.

KENSKI, V.M Educação e tecnologias: O novo ritno da informação. ed. Campinas: Papirus, 2013.

KOCH, I.G.V. Hipertexto e construção do sentido. ALFA: Revista de Linguística, v. 51, n. 1, 2007. Disponível em:< http://seer.fclar.unesp.br/ alfa/ article/ view File/1425/1126> Acesso em 9 fev 2016.

LEMOS, K. M. F. Hiperleitura: Estratégias metacognitivas de leitura em Língua Inglesa. Dissertação (Mestrado Acadêmico em Linguística Aplicada) Universidade Estadual do Ceará. Fortaleza: 2011 . 176 f. Disponível em: < http: //www.uece. br/ posla/dmdocuments/ KeylaMariaFrotaLemos.pdf > Acesso em: 7 set. 2016 .

LÉVY, P. As tecnologias da Inteligência - O futuro do pensamento na era da informática. São Paulo. Editora 34. 1998. Tradução de Carlos Irineu da Costa.

MARCUSCHI, L.A. Linearização, cognição e referência: o desafio do hipertexto. In: Colóquio da Associação Latino-americana de Analistas do Discurso. vol. 4. p. 1-12. 1999. Disponível em:< http://web.uchile.cl/facultades/ filosofia/Editorial/libros/discurso_cambio/17Marcus.pdf > Acesso em 05 de outubro de 2016.

MORAES, L.A.O; ARENA, A.P.B. A leitura em suporte impresso e digital: Modificações nos modos de ler. In: XVI ENDIPE - Encontro Nacional de Didática e Práticas de Ensino - UNICAMP - Campinas: 2012.Disponível em: <http:// www. infoteca.inf.br/endipe/smarty/templates/arquivos_tem plate/upload_arquivos/acervo/docs/1908p.pdf> acesso em 20 fev. 2016.

MORAN, J.M. Como utilizar a internet na educação. Brasília: Ciência da Informação, v. 26, n. 2, p. 1-8, 1997.

ROJO, R.(Org.). Escol@ conectada, os multiletramentos e as tics. 1. ed. São Paulo: Parábola, 2013. 216 p. 
SANTAELLA, L. Linguagens líquidas na era da mobilidade. São Paulo: Paulus, 2007.

SOLÉ, I. Estratégias de Leitura. 6 ed. Porto Alegre: Artmed, 1998.

STORRER. A. Was ist "hyper" am Hypertext? In: KALLMEYER, W. (Org.). Sprache und neve Medien. Berlin, New York: Walter de Gruyter, 2000. p.222-249

Recebido em: 17 de abril de 2018. Aprovado em: 23 de uuturbo de 2018. 